\title{
Long-term Pulmonary Sequelae in Children with Congenital Diaphragmatic Hernia
}

\author{
HANNEKE IJSSELSTIJN, DICK TIBBOEL, WIM J. C. HOP, JAN C. MOLENAAR, \\ and JOHAN C. de JONGSTE
}

Department of Pediatrics, Division of Pediatric Respiratory Medicine; Department of Pediatric Surgery; Department of Epidemiology and Biostatistics; Erasmus University Rotterdam and University Hospital/Sophia Children's Hospital, Rotterdam, the Netherlands

\begin{abstract}
Neonates with congenital diaphragmatic hernia (CDH) often suffer from respiratory insufficiency due to lung hypoplasia and pulmonary hypertension. Artificial ventilation is frequently required, and this leads to a high incidence of bronchopulmonary dysplasia. Long-term follow-up studies have shown persisting airway obstruction. To evaluate the long-term pulmonary sequelae in $\mathrm{CDH}$, we studied $\mathbf{4 0}$ CDH patients of age 7 to 18 yr (median $11.7 \mathrm{yr}$ ) and 65 age-matched controls without CDH and lung hypoplasia who underwent similar neonatal treatment. Mild airway obstruction was found in both groups with more peripheral airway obstruction in CDH patients than in control subjects. Both groups had normal TLC and single-breath carbon monoxide diffusion capacity (DLCO). CDH patients had increased residual volume (RV) and RV/TLC compared with controls. Increased airway responsiveness to methacholine (MCH) was common but bronchoconstriction to inhaled metabisulfite (MBS) was rare both in CDH and control subjects. We conclude that this group of CDH patients has minor residual lung function impairment. Mild airway obstruction and increased airway responsiveness to inhaled MCH but not to MBS suggest that structural changes in distal airways are involved and not autonomic nerve dysfunction. Both artificial ventilation in the neonatal period and residual lung hypoplasia seem important determinants of persistent lung function abnormalities in CDH patients. Ijsselstijn H, Tibboel D, Hop WJC, Molenaar JC, de Jongste JC. Long-term pulmonary sequelae in children with congenital diaphragmatic hernia.

AM I RESPIR CRIT CARE MED 1997;155:174-180.
\end{abstract}

The treatment of prematurely born neonates and children with congenital anomalies has improved during the past $20 \mathrm{yr}$, owing to more sophisticated artificial ventilation techniques and neonatal intensive care. This has resulted in better chances to survive, at the cost of considerable secondary morbidity, e.g., due to bronchopulmonary dysplasia (1). Bronchopulmonary dysplasia (BPD) is a chronic lung disease, which may occur following artificial ventilation in the first weeks after birth. The pathogenesis is multifactorial: barotrauma and high concentrations of inspired oxygen are important $(1,2)$. The incidence of bronchopulmonary dysplasia is highest in prematurely born infants with very low birth weight (2) (up to $85 \%$ ). Long-term follow-up of prematurely born neonates has revealed chronic obstructive lung disease with increased airway responsiveness in adolescents and young adults who required artificial ventilation in the neonatal period (3-9). Congenital diaphragmatic hernia (CDH) is associated with a decreased number of airway generations, and a decreased number of vascular generations (10). Furthermore, pulmonary vascular abnormalities that lead to pulmonary hyper-

(Received in original form June 29, 1995 and in revised form July 1, 1996) Supported by research grant 91.56 from the Nederlands Astma Fonds (Netherlands Asthma Foundation).

Correspondence and requests for reprints should be addressed to $\mathrm{f}$. C. de Jongste, M.D., Ph.D., Department of Pediatrics, Division of Pediatric Respiratory Medicine, Sophia Children's Hospital, Dr. Molewaterplein 60, 3015 G) Rotterdam, the Netherlands.

Am J Respir Crit Care Med Vol 155. pp 174-180, 1997 tension have been described (11). Artificial ventilation with high pressures and a high inspired oxygen fraction $\left(\mathrm{FIO}_{2}\right)$ is often required in the neonatal period.

Bronchopulmonary dysplasia has been described in $33 \%$ of $\mathrm{CDH}$ survivors despite a mean birth weight of nearly $3,000 \mathrm{~g}$ (12). Several follow-up studies found mild airflow obstruction in CDH patients (13-15). Ventilation-perfusion lung scans show diminished perfusion on the ipsilateral side of the diaphragmatic defect, suggesting residual vascular abnormalities in the most hypoplastic lung (14-17). Data on airway responsiveness in CDH are lacking. We hypothesized that children with $\mathrm{CDH}$ have an increased risk to develop chronic lung disease and increased airway responsiveness in later life, and that the prevalence and severity of lung function abnormalities might depend on initial lung hypoplasia. The aim of this study was to evaluate the longterm pulmonary sequelae in children with $\mathrm{CDH}$ and in agematched controls without $\mathrm{CDH}$ and lung hypoplasia who underwent similar neonatal treatment.

\section{METHODS}

Patients

A group of 45 children survived neonatal operative repair of $\mathrm{CDH}$ in our Department of Pediatric Surgery between 1975 and 1986. Forty could be traced and were willing to participate. Operative repair was performed immediately after diagnosis of $\mathrm{CDH}$ in all patients using an abdominal approach. Thirty-five children with left-sided $\mathrm{CDH}$ and one with rightsided CDH had surgery within the first day of life. All patients routinely received antimicrobial prophylaxis perioperatively. Thirty-one children suffered from severe respiratory insufficiency within the first $6 \mathrm{~h}$ 
after birth. We attempted to select two age-matched control patients without $\mathrm{CDH}$ for each CDH patient. The controls were selected from files of the Neonatal and Pediatric Intensive Care Units of the Sophia Children's Hospital in Rotterdam, and the Neonatal Intensive Care Units of the Wilhelmina Children's Hospital in Utrecht and the Free University Hospital in Amsterdam. These control patients were all matched for age at follow-up, and further selected to obtain the best possible match for gestational age, birth weight, duration of artificial ventilation, duration of supplemental oxygen, and sex. To be included in this study the following criteria had to be met by all patients: ( $I$ ) ability to perform lung function tests reproducibly, that is, coefficient of variation in three consecutive measurements of $\mathrm{FEV}_{1}<5 \%$; (2) clinically stable period of at least 3 wk prior to the lung function tests. Exclusion criteria were: any previous thoracic surgery for other reasons than $\mathrm{CDH}$; (congenital) heart disease; lung hypoplasia following prolonged rupture of membranes or renal anomalies with oligohydramnion, or other congenital or acquired disorders of the lungs or airways; inability to follow study instructions; inability to inhale medication adequately. The study was approved by the medical ethical committees of all hospitals involved. Written informed consent was obtained from all parents.

\section{Study Design}

During a prestudy visit a detailed medical history, including personal and family history of atopy and lung disease, was taken. Furthermore, the parents were asked to fill out a standardized questionnaire referring to respiratory symptoms, consultation of physicians, and smoking habits. Physical examination was performed including pulse, blood pressure, respiratory rate, and auscultation of heart and lungs. Two wk before the lung function tests, daily peak flow measurements (Mini Wright Peakflowmeter; Airmed, Harlow, UK) were performed at home in the morning and evening (before taking medication if required), and recorded on a daily record card. The highest value of three consecutive measurements was used for further analysis. The symptoms cough, wheezing, production of sputum, and dyspnea were recorded daily. For each symptom a score from 0 (absent) to three (severe) was given. In this way a maximum score of 96 could be obtained within an 8 -d period. The mean diurnal variation of peak flow (which is the absolute difference between morning and evening value divided by the mean value of morning and evening $\times 100 \%)(18)$ and the total cumulative symptom score from Day 8 to Day 15 were evaluated.

Lung function tests were performed on two separate days within a 1-wk period. Any medication was discontinued $12 \mathrm{~h}$ prior to the tests. To avoid diurnal variation in the measurements, all tests were done in the morning. Spirometry was performed on the first day between 9:00 and 11:00 A.M., and followed by an inhalation provocation test with methacholine $(\mathrm{MCH})$ when the baseline ratio of forced expiratory volume in one second to vital capacity $\left(F E V_{1} / V C\right)$ was at least 0.7 . One hour later, when the baseline $\mathrm{FEV}_{1}$ had returned to at least $90 \%$ of the initial baseline, an inhalation provocation test with metabisulfite (MBS) was performed. Methacholine is a bronchoconstrictor which acts directly at airway smooth muscle, whereas MBS acts indirectly, probably via neuronal pathways (19). On the second day, spirometry and volume-flow curves were recorded before and after maximal bronchodilatation with terbutaline to study reversibility of airway obstruction. Helium dilution spirometry, body plethysmography, and single-breath carbon monoxide diffusion capacity (DLCO) were carried out after bronchodilatation only.

\section{Lung Function and Bronchial Provocation Tests}

Spirometry was performed using a water-sealed spirometer (Volutest Model VLT; Mijnhardt, Zeist, the Netherlands). FEV ${ }_{1}$ and VC were determined as the best of three reproducible measurements. Flow-volume curves were obtained with a heated Fleisch pneumotachograph (Number 3.1184; Godart Statham, Bilthoven, the Netherlands) connected to a computer. FEV, FVC, peak expiratory flow (PEF), and maximal expiratory flows at $25 \%$ of the FVC $\left(\mathrm{MEF}_{25}\right)$ were determined and the best of three consecutive measurements was recorded and expressed as percentage of predicted values (20).

Spirometry and flow-volume curves were performed before and 15 min after $1 \mathrm{mg}$ of terbutaline sulfate, delivered by turbuhaler (Astra Pharmaceuticals, Lund, Sweden) as two inhalations of $500 \mu \mathrm{g}$. After each inhalation the breath was held for $5 \mathrm{~s}$. The change, expressed as percent- age of predicted value, was calculated to evaluate reversibility of any airflow obstruction.

A water-sealed spirometer (Expirograph; Godart Statham, Bilthoven, the Netherlands) filled with a known concentration of helium was used to determine $T L C_{\mathrm{He}}$, residual volume of helium $\left(\mathrm{RV}_{\mathrm{He}}\right), \mathrm{VC}_{\mathrm{He}}$, tidal volume (TV), inspiratory reserve volume (IRV), and expiratory reserve volume (ERV). Helium was allowed to wash in for at least 5 min during normal tidal breathing until a stable concentration was obtained. Volumes were expressed as percentage of the actual TLC. Specific conductance

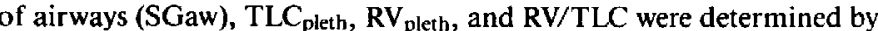
body plethysmography (Jaeger Masterlab, Würzburg, Germany), and the best of three consecutive measurements was recorded. All values, except RV/TLC, were expressed as a percentage of predicted values (20). Carbon monoxide diffusion capacity (Di,co) was measured using a singlebreath method (Jaeger Masterlab, Würzburg, Germany). Reference values for DLCo and DLco corrected for alveolar volume ( $\mathrm{DLCO}_{\mathrm{C}} / \mathrm{V}_{\mathrm{A}}$ ) were based on a study performed in our laboratory in 103 healthy Dutch children (21).

Inhalation provocation was carried out with aerosolized methacholine bromide and sodium metabisulfite $\left(\mathrm{Na}_{2} \mathrm{~S}_{2} \mathrm{O}_{5}\right.$, buffered to $\mathrm{pH} 7.4$ by adding phosphate buffer). $\mathrm{MCH}$ was given in doubling concentrations of 0.15 to $39.2 \mathrm{mg} / \mathrm{ml}$, MBS in doubling concentrations of 2 to $256 \mathrm{mg} / \mathrm{ml}$ as described previously (22). The aerosols were generated by a calibrated De Vilbiss 66 Nebulizer (De Vilbiss Co., Somerset, PA), with closed vent, attached to a French-Rosenthal dosimeter (Laboratory for Applied Immunology, Baltimore, MD) driven by air at $138 \mathrm{kPa}$. The children were instructed to inspire slowly and as deeply as possible. During inspiration the dosimeter was triggered for $0.6 \mathrm{~s}$. After full inspiration, breath was held for $5 \mathrm{~s}$. A total of $20 \mu \mathrm{l}$ of aerosol was delivered to the mouth in 4 consecutive breaths. Mouth doses were 3 to 784 $\mu \mathrm{g}$ for $\mathrm{MCH}$, and 40 to $5,120 \mu \mathrm{g}$ for MBS. Provocations with $\mathrm{MCH}$ and MBS were preceded by inhalation of normal saline. The interval between consecutive doses was $3 \mathrm{~min}$. FEV, was measured in triplicate after each dose-step until the best value had fallen from baseline by at least $20 \%$. The provocative dose that resulted in a $20 \%$ fall in FEV $\left(\mathrm{PD}_{20}\right)$ was calculated by interpolation of the dose-response curve on a loglinear scale.

All lung function tests were performed with subjects in sitting position. All volumes were corrected to BTPS conditions. The equipment and procedures were in accordance with international recommendations (23, 24).

\section{Data Analysis}

Where two control patients were available for a $\mathrm{CDH}$ patient, the mean value of two matched controls was used for paired analysis of the differences between $\mathrm{CDH}$ patients and controls. In the few cases where only one control patient was available, the data of this control patient were used. To exclude the influence of prematurity and atopy as confounding factors, separate analysis of data was performed after excluding all prematurely born infants, and after exclusion of all atopic children. Data of CDH patients and controls were compared with paired $t$ tests, or Wilcoxon's signed-rank test if appropriate. Paired comparisons of percentages were done with the Mantel-Haenszel test. Logarithmic transformation was used in all analyses of $\mathrm{PD}_{20} \mathrm{MCH}$ to approximate a normal distribution. To evaluate the ef fect of age on $\mathrm{PD}_{20} \mathrm{MCH}$, logistic regression was performed. Because only few responded to MBS, these data were described without further statistical analysis. The relation between patient characteristics and lung function results was studied by least squares regression. Multiple regression analysis for continuous outcomes was used to study interaction between variables, i.e., whether the magnitude of the difference between both groups depended on certain other parameters. Correlation coefficients given are Spearman's. Data given are mean \pm SEM unless stated otherwise. Statistical significance was accepted at $1 \%$ level for all tests.

\section{RESULTS}

Patient Characteristics, Questionnaire, and Physical Examination

In the CDH group ( $\mathrm{n}=40$ ), all patients except two had leftsided $\mathrm{CDH}$. Two patients were small for gestational age; three children were born prematurely. Two $\mathrm{CDH}$ patients had only a 
prestudy visit in the hospital: One refused to perform the lung function tests, the second was not able to perform lung function tests due to neurodevelopmental impairment. The data on medical history, physical examination, and the standardized questionnaire of these two CDH patients were included in the analysis. Two matched controls could be recruited for $30 \mathrm{CDH}$ patients, only one control patient could be found for five $\mathrm{CDH}$ patients, while for three CDH patients no suitable control patients could be selected. The 65 control patients had needed neonatal intensive care for: meconium aspiration $(n=29)$, pneumonia $(n=$ 11), persistent fetal circulation $(n=8)$, asphyxia $(n=6)$, respiratory distress syndrome $(n=7)$, amniotic fluid aspiration $(n=3)$, and pneumothorax $(n=1)$. One control patient was small for gestational age at birth, and 24 were born prematurely.

The characteristics of $38 \mathrm{CDH}$ patients who performed lung function tests and 65 control patients are shown in Table 1. The groups were similar with respect to sex, birth weight, duration of artificial ventilation, and duration of oxygen supply. Older $\mathrm{CDH}$ patients had been ventilated shorter than younger $\mathrm{CDH}$ patients $(r=-0.45 ; p=0.005)$. Mean gestational age was 39.6 wk in the $\mathrm{CDH}$ group which was slightly higher compared with $37.7 \mathrm{wk}$ in the control group. The median maximal $\mathrm{FIO}_{2}$ was 0.5 in $\mathrm{CDH}$ and 0.95 in control patients ( $\mathrm{p}<0.001$ ). Ten $\mathrm{CDH}$ patients underwent pressure-controlled ventilation with median maximal inspiratory peak pressures of $37.5 \mathrm{~cm} \mathrm{H}_{2} \mathrm{O}$ (range 20 to $55 \mathrm{~cm} \mathrm{H}_{2} \mathrm{O}$ ); all other $\mathrm{CDH}$ patients underwent volume-controlled ventilation, and peak pressure values could not be retraced. Median maximal inspiratory peak pressures available in 35 control patients was $35 \mathrm{~cm} \mathrm{H}_{2} \mathrm{O}$ (range 17 to $55 \mathrm{~cm} \mathrm{H}_{2} \mathrm{O}$ ). Eight $\mathrm{CDH}$ patients ( 7 term) and six control patients $(3 \mathrm{term})$ fulfilled the criteria of BPD according to Bancalari (2) (NS): They had been ventilated within the first week of life and were still oxygendependent at the age of $28 \mathrm{~d}$. Eight percent of the CDH children and $23 \%$ of control patients had a history of atopy (NS). The family history (first and second degree) for atopy or atopic lung disease was positive in $54 \%$ of $\mathrm{CDH}$ patients and in $52 \%$ of control patients (Table 1).

At the time of assessment one $\mathrm{CDH}$ patient and three controls were using inhaled corticosteroids. Two $\mathrm{CDH}$ patients and one control were using a $\beta_{2}$-agonist on demand. The medical history revealed lung symptoms within the last year in 11 of $40 \mathrm{CDH}$ patients and 11 of 65 control patients (NS). Respiratory symptoms within the first three years of life were reported for 17 of $39 \mathrm{CDH}$ patients and 24 of 64 controls (NS). Symptoms of wheezing and dyspnea during the past 12 mo were reported by $23 \%$ of the CDH patients and $20 \%$ of controls (NS). Limitation of exercise endurance was mentioned by $18 \%$ of the $\mathrm{CDH}$ group

TABLE 1

PATIENT CHARACTERISTICS*

\begin{tabular}{lcc}
\hline & $\mathrm{CDH}$ & Control without CDH \\
\hline Number & $38(21$ male) & $65(44$ male) \\
Age at follow-up, yr & $11.7(7.4-17.6)$ & $12.1(7.7-18.2)$ \\
Gestational age, wk & $40(28-43)$ & $38(29-42)$ \\
Birth weight, g & 3,275 & 2,950 \\
& $(1,000-4,300)$ & $(1,250-4,200)$ \\
Ventilation, d & $4.0(0-49)$ & $4.3(0-25)$ \\
Supplemental oxygen, d & $11.0(0-187)$ & $10.0(0-38)$ \\
Maximal Fio & $0.5(0.21-1)$ & $0.95(0.21-1)$ \\
Atopic history positive & $3(8 \%)$ & $15(23 \%)$ \\
Family history positive & $20(54 \%)$ & $33(52 \%)$ \\
(atopy, lung disease) & & \\
\hline
\end{tabular}

* Data given are numbers of patients or median (range). Duration of oxygen supply is expressed as the total number of days, including days of artificial ventilation. and $6 \%$ of control patients (NS). Eighteen percent of CDH patients and $16 \%$ of controls had consulted a physician for respiratory symptoms during the past year (NS). Two children (one in each group) smoked themselves, whereas smoking occurred in $62 \%$ of the households in the CDH group and in $41 \%$ of the control group (NS). Separate analysis of all children who were born at term resulted in similar results for all items mentioned earlier. The median total respiratory symptom score was 0 in $\mathrm{CDH}$ (range 0 to 24 ) and 0.8 in control patients (range 0 to $32 ; \mathrm{NS}$ ). Physical examination showed mild funnel-shaped chest in $20 \%$ of the CDH patients and in $12 \%$ of control patients (NS). No wheezing was present in any of the children. Daily peak flow registration showed a similar median variability of $4.4 \%$ in $\mathrm{CDH}$ (range 2 to $17.7 \%$ ) and $4.8 \%$ in control patients (range 1.9 to $12.9 \%$; NS). The mean total respiratory symptom scores, the findings of physical examination, and daily peak flow registrations were not significantly different after exclusion of prematurely born children, or after exclusion of atopic subjects.

\section{Lung Function}

Analysis was performed on data from $35 \mathrm{CDH}$ patients and 65 matched control patients. Spirometry showed a significantly lower $\mathrm{FEV}_{1} / \mathrm{VC}$ in $\mathrm{CDH}$ compared with controls before bronchodilatation (Table $2 ; \mathrm{p}=0.01$ ). Flow-volume curves showed normal values for FVC and PEF before and after bronchodilatation in both groups (data not shown). FEV, was significantly lower in CDH patients compared with controls before and after bronchodilatation $(84 \pm 3$ versus $95 \pm 2$, and $92 \pm 3$ versus $101 \pm$ $2 \%$ predicted, respectively). The percentage of patients with abnormally low $\mathrm{FEV}_{1}$ and $\mathrm{MEF}_{25}$ values $(<-1.96 \mathrm{SD}$ from predicted) was high in both groups: FEV, was abnormal in $67 \%$ of $\mathrm{CDH}$ patients and $25 \%$ of controls before bronchodilatation, and in $47 \%$ of $\mathrm{CDH}$ patients and $22 \%$ of controls after bronchodilatation. $\mathrm{MEF}_{25}$ was abnormally low in $\mathrm{CDH}$ before and after bronchodilatation in $79 \%$ and $59 \%$ and in controls in $41 \%$ and $22 \%$ respectively. After $1 \mathrm{mg}$ of inhaled terbutaline flow-volume curves showed a significant increase in $\mathrm{FEV}_{1}$ and $\mathrm{MEF}_{25}$ both in $\mathrm{CDH}$ and in controls (Table $2 ; \mathrm{p}<0.001$ ). $\mathrm{CDH}$ patients and controls showed no significant differences in reversibility of airflow obstruction (Table 2).

Body plethysmography showed a significantly higher mean $\mathrm{RV}_{\text {pleth }}$ and $\mathrm{RV} / \mathrm{TLC}_{\text {pleth }}$ in $\mathrm{CDH}$ than in control patients (Table $2 ; \mathrm{p}=0.001$ and 0.006 , respectively). SGaw was $181 \pm 15 \%$ predicted in $\mathrm{CDH}$ and $156 \pm 12 \%$ predicted in controls (NS). Air trapping was estimated from the difference between $\mathrm{TLC}_{\text {pleth }}$ and $\mathrm{TLC}_{\mathrm{He}}$ : Mean trapped air was $5 \pm 0.5 \%$ of $\mathrm{TLC}_{\mathrm{pleth}}$ in $\mathrm{CDH}$ and $3 \pm 0.6 \%$ in controls (NS). RV/TLC $\mathrm{He}$ was $26 \pm 1 \%$ in $\mathrm{CDH}$ and $23 \pm 1 \%$ in controls $(\mathrm{p}=0.006)$. No differences in ERV, TV, and IRV were found between the groups.

Duco was measured in 17 matched couples and was $100 \pm$ $3 \%$ predicted in $\mathrm{CDH}$ and $105 \pm 2 \%$ predicted in control patients (NS). DLCo/VA was $93 \pm 3 \%$ predicted in $\mathrm{CDH}$ and $101 \pm$ $2 \%$ predicted in controls (NS).

Separate analysis of term born patients showed similar percentage of predicted values for all lung function tests. In controls spirometric $\mathrm{FEV}, / \mathrm{VC}$ before and after bronchodilatation were significantly lower (differences of means both 5 ) in the atopic children than in nonatopic children. The same was true of $\mathrm{MEF}_{25}$ (difference of means before and after bronchodilatation, respectively, $14 \%$ and $24 \%$ ). Abnormal $\mathrm{MEF}_{25}$ was observed in $22 \%$ of term born controls without an atopic history, irrespective of bronchodilatation.

\section{Airway Responsiveness}

In four $\mathrm{CDH}$ patients and in four controls $\mathrm{FEV}_{1} / \mathrm{VC}$ was less 
TABLE 2

LUNG FUNCTION RESULTS IN CDH AND IN MATCHED CONTROLS*

\begin{tabular}{|c|c|c|c|c|c|}
\hline & & & $\begin{array}{l}\text { Before } \\
\text { Broncho- } \\
\text { dilatation }\end{array}$ & $\begin{array}{c}\text { After } \\
\text { Broncho- } \\
\text { dilatation }\end{array}$ & $\begin{array}{l}\text { Change } \\
\text { (\% pred) }\end{array}$ \\
\hline \multirow[t]{4}{*}{ Spirometry } & $\mathrm{CDH}$ & $\mathrm{FEV}_{1}$ & $89 \pm 3$ & $96 \pm 3$ & $7 \pm 1$ \\
\hline & & $\mathrm{FEV}_{1} / \mathrm{VC}$ & $77 \pm 2^{\dagger}$ & $83 \pm 1$ & \\
\hline & Control & FEV & $96 \pm 2$ & $103 \pm 2$ & $7 \pm 1$ \\
\hline & & $\mathrm{FEV}_{1} / \mathrm{VC}$ & $82 \pm 1$ & $86 \pm 1$ & \\
\hline \multirow[t]{4}{*}{ Flow-volume curves } & $\mathrm{CDH}$ & $\mathrm{FEV}_{1}$ & $84 \pm 3^{\dagger}$ & $92 \pm 3^{\dagger}$ & $8 \pm 1$ \\
\hline & & $\mathrm{MEF}_{25}$ & $52 \pm 4^{\dagger}$ & $67 \pm 5^{\dagger}$ & $16 \pm 2$ \\
\hline & Control & FEV $_{1}$ & $95 \pm 2$ & $101 \pm 2$ & $6 \pm 1$ \\
\hline & & $\mathrm{MEF}_{25}$ & $70 \pm 4$ & $92 \pm 3$ & $21 \pm 3$ \\
\hline \multirow[t]{6}{*}{ Body plethysmography } & $\mathrm{CDH}$ & TLC & & $104 \pm 3$ & \\
\hline & & RV & & $125 \pm 5^{\dagger}$ & \\
\hline & & $\mathrm{RV} / \mathrm{TLC}$ & & $29 \pm 1 \dagger$ & \\
\hline & Control & TLC & & $99 \pm 2$ & \\
\hline & & RV & & $105 \pm 3$ & \\
\hline & & $\mathrm{RV} / \mathrm{TLC}$ & & $23 \pm 1$ & \\
\hline \multirow[t]{4}{*}{ Diffusion capacity } & $\mathrm{CDH}$ & DLco & & $100 \pm 3$ & \\
\hline & & $\mathrm{DlCO} / \mathrm{VA}_{\mathrm{A}}$ & & $93 \pm 3$ & \\
\hline & Control & DLCo & & $105 \pm 2$ & \\
\hline & & Dico/va & & $101 \pm 2$ & \\
\hline
\end{tabular}

* Values are mean \pm SEM. All data are expressed as percentage of predicted, except FEV $/ V C$, and RV/TLC. Spirometry and flow-volume curves are shown before and after inhalation of $1 \mathrm{mg}$ of terbutaline, whereas body plethysmography was performed after bronchodilation only.

† Significant difference between $\mathrm{CDH}$ and control patients in the same treatment group (with or without terbutaline), $p<0.01$.

than 0.7 , and hence no challenge test was done. Inhalation provocation was performed in $32 \mathrm{CDH}$ patients and in 56 controls. Inhalation of $\mathrm{MCH}$ resulted in a $20 \%$ or more decrease of $\mathrm{FEV}_{1}$ in $56 \%$ of $\mathrm{CDH}$ patients and in $38 \%$ of controls (NS). The individual $\mathrm{PD}_{20} \mathrm{MCH}$ values are shown in Figure $1 . \mathrm{PD}_{20} \mathrm{MCH}$ $<150 \mu \mathrm{g}$, which is more than $2 \mathrm{SD}$ below the mean value in healthy children (25), was found in $38 \%$ of $\mathrm{CDH}$ patients and in $23 \%$ of controls (NS). Similar results were found after exclu-

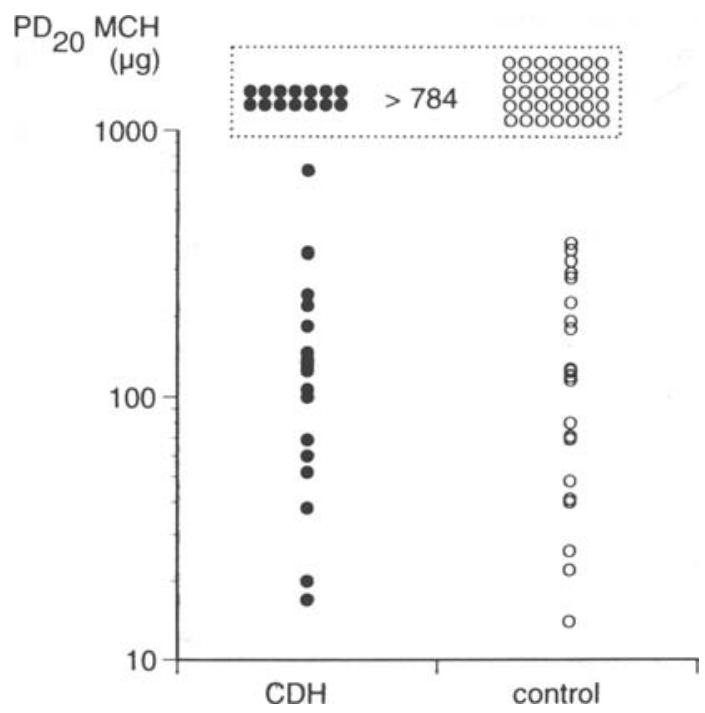

Figure 1. Inhalation provocation with methacholine $(\mathrm{MCH})$ in $\mathrm{CDH}$ and in control patients. The provocative dose that resulted in $20 \%$ decrease of $\mathrm{FEV}_{1}$ is indicated for $\mathrm{MCH}$ on a logarithmic scale. $\mathrm{CDH}$ patients are shown as closed circles and controls as open circles. The highest dose of $\mathrm{MCH}$ was $784 \mu \mathrm{g}$. Nonrespondents are indicated in the box. sion of prematures and atopic children. The prevalence of increased airway responsiveness to MBS was much lower than to MCH: Only two CDH patients and six controls showed a $20 \%$ or more decrease in FEV, after inhalation of MBS. PD $_{20}$ MBS was 1,100 and $195 \mu \mathrm{g}$ in the two $\mathrm{CDH}$ respondents; the median $\mathrm{PD}_{20} \mathrm{MBS}$ in six controls was $765 \mu \mathrm{g}$. After exclusion of prematurely born children two $\mathrm{CDH}$ and four control respondents were left; after exclusion of atopic children only one respondent to inhalation of MBS was present in each group. No difference in the prevalence of increased responsiveness to $\mathrm{MCH}$ and MBS was found between $\mathrm{CDH}$ patients and controls with or without a history of atopy, and the same was true for $\mathrm{PD}_{20} \mathrm{MCH}$ and $\mathrm{PD}_{20} \mathrm{MBS}$ in respondents. No relation between positive challenge tests and a positive family history for lung disease or atopy was apparent in $\mathrm{CDH}$ and control patients.

\section{Correlation between Lung Function Results and Other Patient Characteristics}

This analysis was performed in $38 \mathrm{CDH}$ patients and 65 controls. The results of the lung function tests and the prevalence of increased airway responsiveness on the one hand, and gestational age, birth weight, maximal $\mathrm{FIO}_{2}$, or parental smoking habits on the other hand did not correlate for either group. In $\mathrm{CDH}$ the duration of artificial ventilation correlated negatively with spirometric FEV 1 before and after bronchodilatation (Figure 2), spirometric VC before and after bronchodilatation, $\mathrm{FEV}_{1}$ and FVC in flow-volume curves after bronchodilatation, and $\mathrm{VC}_{\text {pleth }}$. All slopes resulting from linear regression analysis of lung function parameters against duration of ventilation in $\mathrm{CDH}$ patients were between -1.0 and $-1.2 \%$ predicted per day of ventilation ( $\mathrm{p}<0.01$ in all cases), whereas no significant slopes were found in control patients (slopes varied from -0.3 to 0.3 ). In addition, $\mathrm{CDH}$ patients and control were grouped according to whether or not they had been ventilated for at least $7 \mathrm{~d}$. Controls who had been ventilated for less than $7 \mathrm{~d}$ had similar lung function results as those who had been ventilated for at least $7 \mathrm{~d}$. However, $\mathrm{CDH}$ patients who had been ventilated for $7 \mathrm{~d}$ or more had significantly lower $\mathrm{FEV}_{1}$ and VC (spirometry and flowvolume curves, before and after bronchodilatation), PEF before

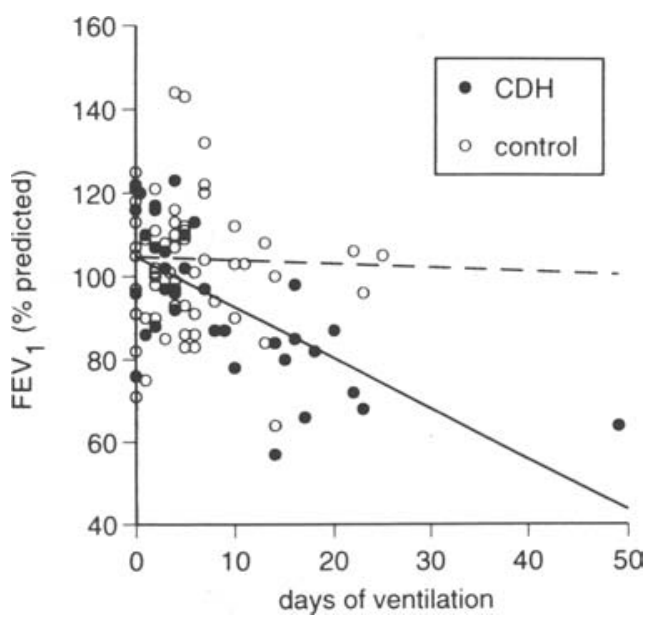

Figure 2. Relation between duration of artificial ventilation (days) and FEV $_{1}$ (expressed as percentage of predicted) after bronchodilatation with $1 \mathrm{mg}$ of inhaled terbutaline measured by spirometry in $\mathrm{CDH}$ (closed circles) and controls (open circles). The regression lines are indicated for both groups: solid line for $\mathrm{CDH}(y=103.03-1.12$ * ventilation; $p=0.0001)$ and dashed line for controls $(y=103.14$ $0.02 *$ ventilation; $p=0.97$ ). 
bronchodilatation, and $\mathrm{MEF}_{2 \mathrm{~s}}$ after bronchodilatation than $\mathrm{CDH}$ patients who had been ventilated for up to $7 \mathrm{~d}$. $\mathrm{CDH}$ patients ventilated for at least $7 \mathrm{~d}$ had significantly lower $\mathrm{TLC}_{\mathrm{He}}$, $\mathrm{TLC}_{\text {pleth}}, \mathrm{VC}_{\text {pleth }}$, and higher $\mathrm{RV} / \mathrm{TLC} \mathrm{Cleth}_{\text {than }}$ those who had been ventilated shorter (Table 3 ). Dico was $93 \pm 4 \%$ predicted in $\mathrm{CDH}$ patients ventilated for up to $7 \mathrm{~d}$ and $98 \pm 4 \%$ in those who had been ventilated for $7 \mathrm{~d}$ or more (NS). Both for CDH and control patients a negative correlation was found between the duration of oxygen supply and FEV, and VC before and after bronchodilatation in spirometry, FVC before and after bronchodilatation, $\mathrm{FEV}_{1}$ before bronchodilatation in flow-volume curves, $\mathrm{TLC}_{\text {pleth }}, \mathrm{TLC} \mathrm{C}_{\mathrm{He}}, \mathrm{VC}_{\text {pleth }}$, and RV/TLC $\mathrm{C}_{\text {pleth }}$. Similar correlations were found after exclusion of children who were born prematurely and/or had a positive atopic history. Age at followup in CDH and in controls correlated positively with PEF before and after bronchodilatation. In $\mathrm{CDH}$, the probability to have a positive response to inhalation of $\mathrm{MCH}$, i.e., $\mathrm{PD}_{20} \mathrm{MCH}<784$ $\mu \mathrm{g}$, correlated negatively with age $(\mathrm{p}=0.001$; Figure 3$)$. The same was true for the probability to have a $\mathrm{PD}_{20} \mathrm{MCH}<150 \mu \mathrm{g}(\mathrm{p}=$ 0.004 ; Figure 3). No significant relation between the presence and the magnitude of $\mathrm{PD}_{20} \mathrm{MCH}$ and age could be shown for control patients. The relations of these parameters with age, however, did not differ significantly between the two groups. Children who had respiratory symptoms during the first 3 yr of life or within the last year had significantly lower $\mathrm{FEV}_{1} / \mathrm{VC}, \mathrm{FEV}_{1}$ (spirometry and flow-volume curves), $\mathrm{PEF}$, and $\mathrm{MEF}_{25}$ before and after bronchodilatation compared with children without respiratory symptoms. Similar results were found after exclusion of prematures and atopic subjects.

\section{DISCUSSION}

We found mild obstructive lung function abnormalities and a high prevalence of increased airway responsiveness to methacholine both in children with neonatal repair of $\mathrm{CDH}$ and, to a lesser extent, in age-matched controls. The controls underwent similar neonatal treatment but had not been operated on for $\mathrm{CDH}$ and did not have lung hypoplasia. Both groups showed normal total lung capacity and normal diffusion capacity under resting conditions, suggesting that no important lung function impairment had resulted from $\mathrm{CDH}$.

Interpretation of long-term pulmonary sequelae after neonatal repair of $\mathrm{CDH}$ has been difficult because of the lack of comparative long-term data on lung function abnormalities in ventilated term neonates without $\mathrm{CDH}$. The present study is the first in which lung function data of $\mathrm{CDH}$ patients are compared with

TABLE 3

LUNG FUNCTION IN CDH PATIENTS VENTILATED FOR LESS THAN 7 D AND FOR 7 D OR MORE*

\begin{tabular}{|c|c|c|}
\hline Parameter & $<7 \mathrm{~d}(n=23)$ & $>7 \mathrm{~d}(n=15)$ \\
\hline $\begin{array}{l}\text { Duration of ventilation, } \\
\text { median (range) }\end{array}$ & $2(0-6) d$ & $16(7-49) d$ \\
\hline \multicolumn{3}{|l|}{ Spirometry } \\
\hline $\mathrm{FEV}_{1}$ before $\mathrm{BD}$ & $98 \pm 3$ & $74 \pm 4$ \\
\hline $\mathrm{FEV}_{1}$ after $\mathrm{BD}$ & $105 \pm 3$ & $79 \pm 3$ \\
\hline$V C$ before $B D$ & $103 \pm 3$ & $83 \pm 3$ \\
\hline \multicolumn{3}{|l|}{ Flow-volume curves } \\
\hline PEF before BD & $100 \pm 4$ & $80 \pm 5$ \\
\hline $\mathrm{MEF}_{2 S}$ after $\mathrm{BD}$ & $76 \pm 6$ & $48 \pm 7$ \\
\hline \multicolumn{3}{|l|}{ Body plethysmography } \\
\hline TLC & $108 \pm 3$ & $96 \pm 3$ \\
\hline RV/TLC & $27 \pm 1$ & $33 \pm 2$ \\
\hline
\end{tabular}

* Values are mean \pm SEM. All data are expressed as percentage of predicted, except RV/TLC. Significant differences were found for all parameters $(p<0.01)$.
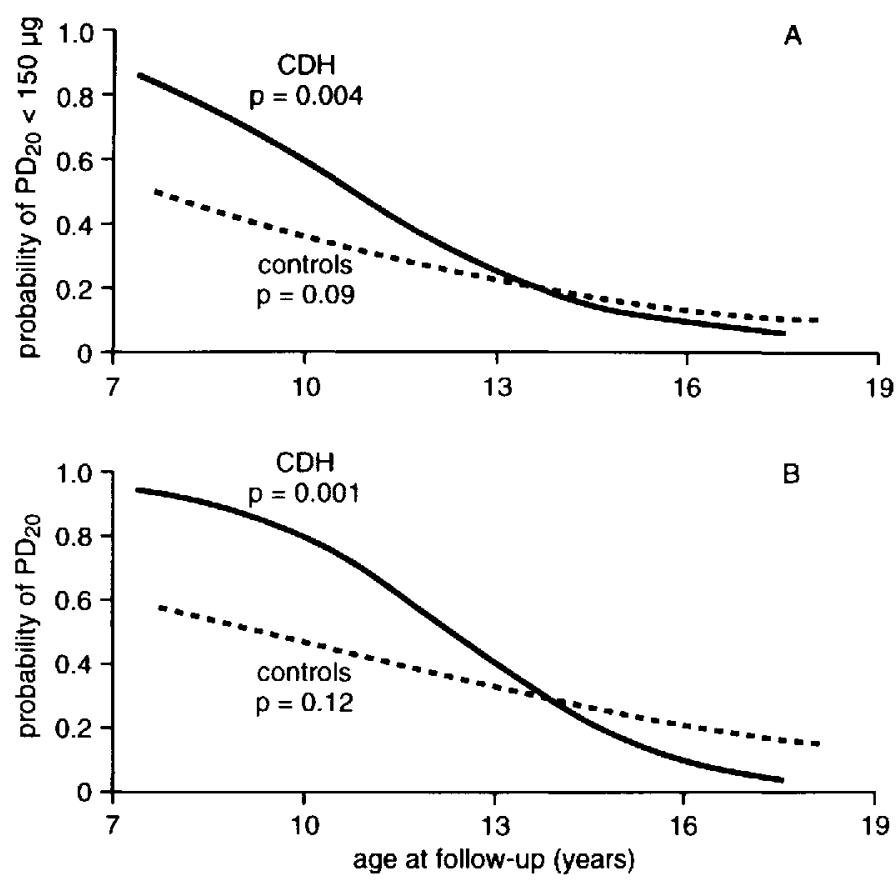

Figure 3. Relation between the probability to have $\mathrm{PD}_{20} \mathrm{MCH}<150$ $\mu \mathrm{g}(A)$ or to reach $\mathrm{PD}_{20} \mathrm{MCH}(B)$ and age at follow-up in $\mathrm{CDH}$ and in control patients.

those of age-matched controls who were selected for the best possible match for gestational age, birth weight, duration of artificial ventilation and oxygen supply, and sex. Gestational age was slightly, but significantly lower in the control group and it could be argued that this may explain differences in lung function. However, mean gestational age was more than $37 \mathrm{wk}$ in both groups (37.7 versus $39.6 \mathrm{wk}$ ), and similar results were found after separate analysis of term born children. Therefore differences in lung function between the two groups can not be attributed to differences in gestational age. The maximal $\mathrm{FI}_{2}$ was significantly lower in $\mathrm{CDH}$ than in controls, but did not correlate with the measured lung function parameters. The groups were similar with respect to atopic history, positive family history for atopy or lung diseases, and smoking habits. Therefore, these potential confounding factors cannot explain differences in lung function between $\mathrm{CDH}$ and controls either.

We found more peripheral airway obstruction in $\mathrm{CDH}$ patients than in controls, as was apparent from decreased $\mathrm{FEV}_{1} / \mathrm{VC}$ and $\mathrm{MEF}_{25}$, high percentages of abnormal $F E V_{1}$, and $\mathrm{MEF}_{25}$, and increased RV/TLC. In control patients mild airflow obstruction was suggested by decreased $\mathrm{MEF}_{25}$, and abnormal FEV ${ }_{1}$ and $\mathrm{MEF}_{2 \mathrm{~s}}$ in more than $20 \%$ of cases after exclusion of the prematurely born and atopic children. Separate analysis of term born children without a history of atopy indicated that in controls $F E V_{1} / V C$ and $M F_{25}$ were higher in nonatopic children compared with atopic children. Such a difference could not be demonstrated for the CDH group (with only three children having a history of atopy). There was no difference in reversibility of airway obstruction between the groups. The mean reversibility of FEV , was within the normal range seen in healthy individuals (24). Mild airflow obstruction $(13,14,26)$ or normal spirometry (17) were reported in school age children before 1976. A number of these children were operated on after the perinatal period at ages up to $2 \mathrm{yr}$. An unspecified number were ventilated postoperatively. It is likely that the number was small. In patients born subsequently, Falconer and coworkers (15) found evidence of re- 
duced expiratory flows at $50 \% \mathrm{VC}$. Seven of his 19 children had been ventilated for $4 \mathrm{~d}$ or more.

Airflow obstruction has been described in several follow-up studies of premature children with and without $\operatorname{BPD}(3-5,9,27)$, but normal spirometric results have also been reported (8). The airflow obstruction described in nonventilated $\mathrm{CDH}$ patients suggests residual hypoplasia of lungs or airways. Abnormal tracheal or bronchial cartilage has been described in $\mathrm{CDH}$ (28). This may enhance airflow obstruction as a result of inadequate support, and, hence, dynamic compression of the intrathoracic airway during forced expiration. In addition, functional impairment may have resulted from airway damage due to artificial ventilation and oxygen treatment in ventilated $\mathrm{CDH}$ patients.

TLC and VC were normal in our study, consistent with the observations of others $(13,14)$, although restrictive defects have also been observed (29). Residual volume was marginally elevated in our study in that of Reid and Hutcherson (29).

Normal TLC and VC in CDH suggest that absence of residual lung hypoplasia and it may well be that the compensatory lung growth takes place during the first year of life (30). However, the number of alveoli may still be reduced. Therefore we also measured diffusion capacity, which is a measure of the diffusion surface and consequently of the alveolar surface. Dico and Dico corrected for alveolar volume were normal in CDH and in control patients. This suggests the presence of a normal diffusion surface area under resting conditions at long-term followup in $\mathrm{CDH}$, as described previously (14). Exercise stress testing with measurement of DLco would be necessary to reveal the functional significance of a possible residual lung hypoplasia. In favor of residual lung hypoplasia are mild airflow obstruction, decreased lung perfusion on the ipsilateral side of the diaphragmatic defect $(14,16,29)$, the observation that anatomic formation of further generations of airways and conducting vessels does not develop after $16 \mathrm{wk}$ gestation (31), and findings of longterm lung morphology after neonatal repair of CDH: Normal total lung volume, but an abnormal lung structure, has been described in three cases of $\mathrm{CDH}$ at autopsy after 2.5 to $64 \mathrm{mo} \mathrm{(32,}$ 33). Whereas the total number of alveoli was either decreased $(32,33)$ or normal $(33)$, the alveolar size was increased in all cases, especially on the ipsilateral side. The lower DLCo/VA in our CDH patients compared with controls may indicate persistence of such morphologic abnormalities. The normal $\mathrm{DL}_{\mathrm{CO}}$ in $\mathrm{CDH}$ patients and in age-matched ventilated controls suggests that diffusion capacity is not severely affected by lung damage caused by artificial ventilation.

There are no data on airway responsiveness at long-term follow-up in children with $\mathrm{CDH}$. We found a high prevalence of $\mathrm{MCH}$ responsiveness both in $\mathrm{CDH}(56 \%)$ and in control patients $(38 \%)$, irrespective of an atopic history or a positive family history for atopy or lung disease. Several investigators have described increased airway responsiveness to inhalation of $\mathrm{MCH}$ or histamine in prematures following artificial ventilation $(5,6,27)$. A high prevalence of exercise-induced bronchospasm was found in a group of term born children with meconium aspiration syndrome following a short period of artificial ventilation (34). The high prevalence of increased airway responsiveness to $\mathrm{MCH}$, together with the smaller number of positive respondents after inhalation of MBS, suggests that the mechanism of airway narrowing in our patients is different from that in asthmatic subjects where both challenges correlate well (35). Residual structural narrowing of distal airways or airway smooth muscle hypertrophy may explain our findings, because these abnormalities would lead to increased airway responsiveness only as a result of the altered airway geometry (36). Because no differences were found between $\mathrm{CDH}$ patients and controls, it can be assumed that artificial ventilation during the neonatal period is a more likely cause of these abnormalities than lung or airway hypoplasia in $\mathrm{CDH}$. We found that the prevalence of airway responsiveness to $\mathrm{MCH}$ was significantly lower in older $\mathrm{CDH}$ patients. This may reflect the natural history of airway responsiveness following artificial ventilation in the neonatal period, although our cross-sectional data do not allow for this assumption. Another possible explanation is that older patients had been artificially ventilated for a shorter period of time because of the restricted intensive care treatment in those days. Therefore $\mathrm{CDH}$ patients born earlier, e.g., between 1975 and 1980, and who survived their neonatal period, may have had less severe lung hypoplasia with less structural small airway abnormalities than the children who were born later.

We found a negative correlation between the duration of ventilation and $\mathrm{FEV}_{1}$ at follow-up in $\mathrm{CDH}$. A negative correlation between $F E V_{1}$ and duration of ventilation has been described in follow-up studies of prematures as well $(4,9)$. Previous studies in ventilated prematures without BPD suggest that the effect of artificial ventilation is independent of gestational age $(8,9)$. However, most prematures with very low birth weight will require artificial ventilation for a longer period of time and are more likely to develop BPD (2). A high incidence of BPD in CDH patients has been reported by Bos and coworkers (12) who studied a group of $\mathrm{CDH}$ survivors born between 1980 and 1989 with respiratory insufficiency within the first $6 \mathrm{~h}$ after birth. The children in our study group were born between 1975 and 1986 when extracorporeal membrane oxygenation and high-frequency oscillatory ventilation were not available. It can be assumed that especially $\mathrm{CDH}$ patients with less severe lung hypoplasia survived at that time, whereas the children with severe lung hypoplasia and severe persistent pulmonary hypertension may have died even before reaching the Pediatric Surgical Intensive Care Unit. This assumption is supported by the fact that our group of $\mathrm{CDH}$ patients had a median duration of ventilation of only $4 \mathrm{~d}$ with a mean maximal $\mathrm{Fro}_{2}$ of 0.5 . That we found lung function abnormalities especially in $\mathrm{CDH}$ patients who were ventilated for at least $7 \mathrm{~d}$ suggests that respiratory morbidity may well increase in those children with more severe lung hypoplasia, who will require artificial ventilation for longer periods of time and who presently survive $\mathrm{CDH}(3,8,9)$.

In conclusion, we found mild obstructive lung function abnormalities in $\mathrm{CDH}$ and also, but to a lesser extent, in carefully matched control patients. The difference between $\mathrm{CDH}$ patients and controls could not be explained by differences in patient characteristics and could therefore be due to residual lung hypoplasia, and/or to anatomic and functional changes of the thoracic wall, the diaphragm, or the airway cartilage in the CDH patients. $\mathrm{CDH}$ patients showed no important reduction of lung volume and diffusion capacity under resting conditions. Airway responsiveness to $\mathrm{MCH}$, but not to MBS, was increased in both groups, suggesting that the mechanism of airway narrowing was different from that in asthmatics. We speculate that structural abnormalities in distal airways are responsible for the high incidence of increased airway responsiveness. Our data suggest that not only residual lung hypoplasia, but also neonatal intensive care treatment contribute to the persisting airway obstruction and increased airway responsiveness in CDH patients.

\footnotetext{
Acknowledgments: The writers thank the Department of Neonatology of the Sophia Children's Hospital (head: Prof. Dr. P. I. J. Sauer, former head: Prof. Dr. I. W. Mettau), Dr. H. A. A. Brouwers and Drs. J. van der Laag from the Wilhelmina Children's Hospital Utrecht, and Prof. Dr. H. N. Lafeber and Drs. J. F. Samsom from the Free University Hospital Amsterdam for the opportunity to recruit control patients. The writers also thank the staff from the lung function laboratory of the Sophia Children's Hospital for their skillful assistance, and the patients and their parents for their participation.
}

\section{References}

1. Northway, W. H., Jr., R. C. Rosan, and D. Y. Porter. 1967. Pulmo- 
nary disease following respiratory therapy of hyaline-membrane disease. N. Engl. J. Med. 267:357-367.

2. Bancalari, E., and T. Gerhardt. 1986. Bronchopulmonary dysplasia. Pediatr. Clin. North. Am. 33:1 23.

3. Northway, W. H., Jr., R. B. Moss, K. B. Carlisle, B. R. Parker, R. L. Popp, P. T. Pitlick, I. Eichler, R. L. Lamm, and B. W. Brown, Jr. 1990. Late pulmonary sequelae of bronchopulmonary dysplasia. $N$. Engl. J. Med. 323:1793-1799.

4. Bader, B., A. D. Ramos, C. D. Lew, A. C. G. Platzker, M. W. Stabile, and T. G. Keens. 1987. Childhood sequelae of infant lung disease: exercise and pulmonary function abnormalities after bronchopulmonary dysplasia. J. Pediatr. 110:693-699.

5. Blayney, M., E. Kerem, H. Whyte, and H. O'Brodovich. 1991. Bronchopulmonary dysplasia: improvement in lung function between 7 and 10 years of age. J. Pediatr. 118:201-206.

6. Chan, K. N., A. Elliman, E. Bryan, and M. Silverman. 1989. Clinical significance of airway responsiveness in children of low birthweight. Pediatr. Pulmonol. 7:251-258.

7. Chan, K. N., Y. C. Wong, and M. Silverman. 1990. Relationship between infant lung mechanics and childhood lung function in children of very low birthweight. Pediatr. Pulmonol. 8:74-81.

8. Hakulinen, A. L., K. Heinonen, E. Länsimies, and O. Kiekara. 1990. Pulmonary function and respiratory morbidity in school-age children born prematurely and ventilated for neonatal respiratory insufficiency. Pediatr. Pulmonol. 8:226-232.

9. Andréasson, B., M. Lindroth, W. Mortensson, N. W. Svenningsen, and B. Jonson. 1989. Lung function eight years after neonatal ventilation. Arch. Dis. Child. 64:108-113.

10. Kitagawa, M., A. Hislop, E. A. Boyden, and L. Reid. 1971. Lung Hypoplasia in congenital diaphragmatic hernia. A quantitative study of airway, artery, and alveolar development. Br. J. Surg. 58:342-346.

11. Naeye, R. L., S. J. Shochat, V. Whitman, and M. J. Maisels, 1976. Unsuspected pulmonary vascular abnormalities associated with diaphragmatic hernia. Pediatrics 58:902-906.

12. Bos, A. P., S. M. Hussein, F. W. J. Hazebroek, D. Tibboel, M. Meradji, and J. C. Molenaar. 1993. Radiographic evidence of bronchopulmonary dysplasia in high-risk congenital diaphragmatic hernia survivors. Pediatr. Pulmonol. 15:231-235.

13. Chatrath, R. R., M. El Shafie, and R. S. Jones. 1971. Fate of hypoplastic lungs after repair of congenital diaphragmatic hernia. Arch. Dis. Child. 46:633-635.

14. Wohl, M. E. B., N. T. Griscom, D. J. Strieder, S. R. Schuster, S. Treves, and R. G. Zwerdling. 1977. The lung following repair of congenital diaphragmatic hernia. J. Pediatr. 90:405-414.

15. Falconer, A. R., R. A. Brown, P. Helms, I. Gordon, and J. A. Baron. 1990. Pulmonary sequelae in survivors of congenital diaphragmatic hernia. Thorax 45:126-129.

16. Jeandot, R., B. Lambert, A. J. Brendel, M. Guyot, and J. L. Demarquez. 1989. Lung ventilation and perfusion scintigraphy in the followup of repaired congenital diaphragmatic hernia. Eur. J. Nucl.Med. 15:591-596.

17. Freyschuss, U., K. Lännergren, and B. Frenckner. 1984. Lung function after repair of congenital diaphragmatic hernia. Acta Paediatr. Scand. 73:589-593.

18. Siersted, H. C., H. S. Hansen, N.-C. G. Hansen, N. Hyldebrandt, G. Mostgaard, and H. Oxhöj. 1994. Evaluation of peak expiratory flow variability in an adolescent population sample. The Odense Schoolchild Study. Am. J. Respir. Crit. Care Med. 149:598-603.

19. Wright, W., G. Zhang, C. M. Salome, and A. J. Woolcock. 1990. Ef- fect of inhaled preservatives on asthmatic subjects. I. Sodium metabisulfite. Am. Rev. Respir. Dis. 141:1400-1404.

20. Zapletal, A., T. Paul, and M. Samánek. 1977. Die Bedeutung heutiger Methoden der Lungenfunktionsdiagnostik zur Feststellung einer $\mathrm{Ob}-$ struktion der Atemwege bei Kindern und Jugendlichen. Z. Erkrank. Atm.-Org. 149:343-371.

21. Stam, H., A. Van de Beek, K. Grünberg, T. Stijnen, H. A. W. M. Tiddens, and A. Versprille. 1996. Pulmonary diffusing capacity at reduced alveolar volumes in children. Pediatr. Pulmonol. 21:84-89.

22. Vandenbossche, L. E., W. C. Hop, and J. C. de Jongste. 1993. Bronchial responsiveness to inhaled metabisulfite in asthmatic children increased with age. Pediatr. Pulmonol. 16:236-242.

23. Sterk, P. J., L. M. Fabbri, Ph. H. Quanjer, D. W. Cockeroft, P. M. O'Byrne, S. D. Anderson, E. F. Juniper, and J.-L. Malo. 1993. Airway responsiveness. Standardized challenge testing with pharmacological, physical and sensitizing stimuli in adults. Report Working Party "Standardization of lung function tests," European Community for Steel and Coal. Official statement of the European Respiratory Society. Eur. Respir. J. 6(Suppl.):53-83.

24. Quanjer, Ph. H., G. J. Tammeling, O. F. Pedersen, R. Peslin, J.-C. Yernault. 1993. Lung volumes and forced ventilatory flows. Report Working Party "Standardization of lung function tests," European Community for Steel and Coal. Official statement of the European Respiratory Society. Eur. Respir. J. 6(Suppl.):5-40.

25. Van Essen-Zandvliet, E. E. M., M. Hughes, H. J. Waalkens, E. J. Duiverman, S. J. Pocock, K. F. Kerrebijn, and the Dutch Chronic Non-Specific Lung Disease Study Group. 1992. Effects of 22 months of treatment with inhaled corticosteroids and/or beta-2-agonists on lung function, airway responsiveness, and symptoms in children with asthma. Am. Rev. Respir. Dis. 146:547-554.

26. Kerr, A. A. 1977. Lung function in children after repair of congenital diaphragmatic hernia. Arch. Dis. Child. 52:902-903.

27. Smyth, J. A., E. Tabachnik, W. J. Duncan, B. J. Reilly, and H. Levison. 1981. Pulmonary function and bronchial hyperreactivity in longterm survivors of bronchopulmonary dysplasia. Pediatrics 68:336-340.

28. Landing, B. H., and T. R. Wells. 1973. Tracheobronchial anomalies in children. Perspect. Pediatr. Pathol. 1:1-32.

29. Reid, I. S., and R. J. Hutcherson. 1976. Long-term follow-up of patients with congenital diaphragmatic hernia. J. Pediatr. Surg. 11:939942.

30. Landau, L. I., P. D. Phelan, G. L. Gillam, E. Coombs, and H. R. Noblett. 1977. Respiratory function after repair of congenital diaphragmatic hernia. Arch. Dis. Child. 52:282-286.

31. Reid, L. 1977. The lung: its growth and remodeling in health and disease. Am. J. Roentgenol. 129:777-788.

32. Hislop, A., and L. Reid. 1976. Persistent hypoplasia of the lung after repair of congenital diaphragmatic hernia. Thorax 31:450-455.

33. Thurlbeck, W. M., K. Kida, C. Langston, M. J. Cowan, J. A. Kitterman, W. Tooley, and H. Bryan. 1979. Postnatal lung growth after repair of diaphragmatic hernia. Thorax 34:338-343.

34. Swaminathan, S., J. Quinn, M. W. Stabile, D. Bader. A. C. G. Platzker, and T. G. Keens. 1989. Long-term pulmonary sequelae of meconium aspiration syndrome. J. Pediatr. 114:356-361.

35. Nichol, G. M., A. Nix, K. F. Chung, and P. J. Barnes. 1989. Characterization of bronchoconstrictor responses to sodium metabisulphite aerosol in atopic subjects with and without asthma. Thorax 44: 1009-1014.

36. Moreno, R. H., J. C. Hogg, and P. D. Paré. 1986. Mechanics of airway narrowing. Am. Rev. Respir. Dis. 133:1171-1180. 